\title{
MODELAGEM DO PARÂMETRO DE INTERAÇÃO BINÁRIA DA EQUAÇÃO PC-SAFT UTILIZANDO REDES NEURONAIS ARTIFICIAIS
}

\author{
J. R. FERREIRA, Y. GUERRIERI*, G. MEYBERG, M. EMBIRUÇU \\ Programa de Pós-Graduação em Engenharia Industrial - PEI \\ Universidade Federal da Bahia \\ E-mail para contato: yuri.guerrieri@ufba.br
}

\begin{abstract}
RESUMO - A modelagem do equilíbrio de fases de soluções poliméricas é uma tarefa complexa, em especial, devido à assimetria de suas moléculas. Dentre os modelos termodinâmicos disponíveis na literatura, a equação de estado PC-SAFT tem apresentado um bom desempenho na modelagem de sistemas poliméricos. Uma equação de estado requer o uso de parâmetros de interação binária (BIP) utilizados para adequar o modelo aos dados experimentais de misturas. BIPs influenciam fortemente as curvas de equilíbrio e conceitualmente engloba todas as interações energéticas entre as moléculas. Devido à complexidade destas interações e a influência da pressão e temperatura, o desenvolvimento de uma correlação precisa é difícil. A proposta do trabalho é apresentar o uso de redes neuronais artificiais (RNA) como uma alternativa à falta de um modelo fenomenológico adequado para calcular o BIP. Para treinamento e teste foram utilizados 311 dados de equilíbrio de soluções binárias de polietileno e etileno da literatura.
\end{abstract}

\section{INTRODUÇÃO}

Um dos maiores desafios na descrição PVT (Pressão-Volume-Temperatura) e do equilíbrio de fases em sistemas complexos é encontrar modelos capazes de descrevê-los contemplando as principais interações entre as moléculas. Tais sistemas podem variar de acordo com: a) a natureza dos compostos (polar ou apolar); b) tamanho dos compostos (moléculas ou macromoléculas como proteínas e polímeros); c) condições de pressão, temperatura e composição do sistema. A necessidade de se desenvolver modelos termodinâmicos capazes de descrever estas complexas interações, responsáveis pelo comportamento do equilíbrio de fases, continua sendo uma grande fonte de estímulo aos pesquisadores. $\mathrm{O}$ estudo dos potenciais intermoleculares existentes entre as moléculas de uma dada substância é de fundamental importância para o bom entendimento das interações existentes, e essas forças (ou potenciais) irão determinar suas propriedades termodinâmicas (Smith et al., 2007). Em especial, a modelagem das interações moleculares em sistemas poliméricos é uma tarefa bastante complexa. Isso ocorre porque as moléculas presentes são muito assimétricas, além da sua polidispersão e o grande peso molecular influenciarem significativamente as interações moleculares. Isso torna a caracterização do sistema e os cálculos de equilíbrio bastante complexos. O equilíbrio de fases de soluções poliméricas, em especial a altas pressões, é geralmente modelado com a utilização de equação de estado (EDE).

A literatura fornece diversas aplicações de diferentes EDE para sistemas poliméricos. 
Um grande avanço nos últimos anos foi uma das modificações mais recentes da teoria SAFT (Statistical Associating Fluid Theory): a equação PC-SAFT (Perturbed-Chain SAFT), desenvolvida por Gross e Sadowski (2001). Em sua essência, ela considera a forma e tamanho das moléculas, além da associação entre elas, e tem apresentado um bom desempenho na modelagem de sistemas poliméricos quando comparado a outras EDEs (Guerrieri et al, 2012). A EDE PC-SAFT, assim como os outros modelos termodinâmicos disponíveis para modelar o equilíbrio de fases para sistemas binários ou multicomponentes, utiliza um parâmetro de ajuste comumente denominado de parâmetro de interação binária (BIP, Binary Interaction Parameter). Em geral, os BIPs são expressos como constantes para um dado sistema binário, independente da natureza dos compostos e das suas condições de temperatura e pressão. Contudo, por vezes essa abordagem não satisfaz de forma plena a modelagem em uma ampla faixa de temperatura e pressão. Sistemas simples, aqueles constituídos por compostos com moléculas simples e que estejam à temperatura e pressão moderadas, são possíveis de serem modelados utilizando um valor constante de BIP.

Até o momento não existem modelos que representem as forças intermoleculares e consequentemente forneça o valor de BIP satisfatoriamente para uma ampla gama de compostos. Em uma revisão bibliográfica recente podemos citar como relevante o trabalho de Haslam et al. (2008), que apresenta expressões matemáticas para representar o BIP em diferentes interações moleculares. Eles estenderam a regra de Hudson-McCoubrey (1960), originalmente aplicada em moléculas simples e apolares, para casos onde a determinação do potencial intermolecular é mais complexa. Entretanto, os BIPs ajustados com os dados experimentais apresentam uma diferença significativa em relação ao predito pela equação. A ausência de modelos fenomenológicos precisos para o cálculo do BIP torna essencial o uso de dados experimentais para o seu ajuste. Isso limita o uso das EDE, principalmente em casos em que os dados experimentais são escassos ou inexistentes. Em situações assim, o uso de modelos empíricos para a predição do BIP é de grande valia. As redes neuronais artificiais (RNA), por exemplo, podem ser uma importante ferramenta na modelagem e predição do BIP, embora o seu uso não permita uma visualização da relação funcional e de proporcionalidade de forma explicita como nos modelos fenomenológicos. Ainda assim, a sua capacidade de modelar sistemas altamente complexos como o estudado aqui, tornam o seu uso um grande atrativo.

As RNA possuem ampla aplicação prática, inclusive na termodinâmica. Prasad e Bhagwat (2002) aplicaram o método para estimar propriedades físicas de compostos orgânicos: temperatura, pressão e volume críticos, e o ponto de ebulição normal. Hosseini et al (2008) usaram RNA e a EDE de Peng-Robinson para estimar as propriedades críticas de misturas de hidrocarbonetos. Os resultados foram comparados com os dados experimentais da literatura. A RNA forneceu melhores resultados que o modelo termodinâmico. Moghadassi et al (2008) aplicaram RNA para predizer propriedades termodinâmicas da amônia saturada e supersaturada a partir de dados da literatura. As mesmas propriedades foram calculadas com as EDEs de Lee Kesler, NRTL, Soave-Redlich-Kwong e Peng-Robinson. Os resultados obtidos foram muito próximos, mostrando que a RNA apresentou uma boa capacidade de predição. Gharagheizi et al (2011a) utilizaram RNA para estimar propriedades críticas de diversas substâncias puras. Foram retiradas da literatura propriedades críticas e fatores acêntricos de aproximadamente 1700 compostos químicos. Gharagheizi et al (2011b) aplicaram redes para predizer a solubilidade de vários compostos químicos em água em torno da temperatura ambiente (293 a $298 \mathrm{~K})$ e à pressão atmosférica, utilizando dados da literatura. Gharagheizi et al (2011c) usaram RNA para predizer a tensão superficial de diversos componentes puros em diferentes temperaturas e à pressão atmosférica. Os autores ressaltaram que, apesar do amplo intervalo de aplicabilidade da 
RNA, a capacidade de predição das propriedades está restrita aos componentes utilizados em seu treinamento. Em outras palavras, ao fornecer as entradas corretas de um determinado composto não utilizado no treinamento, é provável que o valor de saída da rede seja grosseiro. Nami e Deyhimi (2011) utilizaram RNA para predizer os coeficientes de atividade à diluição infinita de solutos orgânicos em líquidos iônicos num intervalo de temperatura de 298 a 363 K. Os dados experimentais foram coletados da literatura. Um ponto positivo encontrado no trabalho foi a capacidade da RNA em predizer o coeficiente de atividade de outros solutos orgânicos, dentro da temperatura utilizada no treinamento. As redes foram usadas também por Sanjari e Lay (2012), que modelaram o fator de compressibilidade de diferentes composições de gás natural usando RNA. Os valores obtidos foram comparados com as EDE de Peng-Robinson e SAFT e outros modelos empíricos propostos na literatura. Yousefi e Karimi (2013) usaram RNA e a EDE Ihm-Song-Mason modificada para predizer o comportamento PVT de polímeros fundidos, obtendo bons resultados em ambos os modelos. Em geral, todos os trabalhos citados obtiveram resultados satisfatórios e propõem o uso de RNA como uma importante ferramenta de predição. Em muitos casos, a saída obtida pela rede neural apresentou um menor desvio relativo em relação aos outros modelos.

O presente trabalho utilizará a abordagem convencional para propor a utilização de RNA para predizer o BIP, que é uma alternativa à falta de modelos adequados disponíveis para seu cálculo. Os BIPs utilizados neste trabalho foram gerados a partir do ajuste de dados experimentais binários de equilíbrio líquido-líquido do sistema PEBD/etileno a alta pressão utilizando a equação de estado PC-SAFT.

\section{MODELAGEM VIA REDE NEURAL}

\subsection{GERAÇÃO DE DADOS DE TREINAMENTO}

Os BIPs utilizados para treinamento da RNA foram gerados a partir do ajuste do modelo PC-SAFT aos dados experimentais de equilíbrio. As Equações 1 e 2 mostram respectivamente uma equação básica de PC-SAFT e a regra de combinação.

$$
\begin{aligned}
& \frac{A^{r e s}}{N \cdot k \cdot T}=\frac{A^{h c}}{N \cdot k \cdot T}+\frac{A^{d i s p}}{N \cdot k \cdot T}+\frac{A^{a s s o c s}}{N \cdot k \cdot T} \\
& \varepsilon_{i j}=\left(1-k_{i j}\right)\left(\varepsilon_{i i} \cdot \varepsilon_{j j}\right)^{1 / 2}
\end{aligned}
$$

onde $A^{\text {res }}$ refere-se à energia livre de Helmholtz residual e os sobrescritos $h c$, disp e assoc representam os termos referentes às contribuições de cadeia rígida, interações de dispersão e de associação, respectivamente. O $\varepsilon_{i j}$ é o parâmetro cruzado que relaciona as interações entre o componente $i$ e o componente $j$ e $k_{i j}$ é o parâmetro de interação binária (PIB). Foram coletados na literatura 311 dados de equilíbrio líquido-líquido do sistema polímero/solvente a alta pressão. Para assegurar que o ajuste não teria efeito do tipo de polímero ou solvente, foi escolhido um único tipo de polímero, neste caso o polietileno de baixa densidade (PEBD) e o etileno como o único tipo de solvente.

Foram coletados dados de equilíbrio do sistema PEDB/etileno em diferentes condições 
de pressão, temperaturae composição, para polímero com diferentes propriedades morfológicas comumente publicadas na literatura: peso molecular médio e polidispersão. A busca por polímeros com diferentes propriedades morfológicas se justifica uma vez que já é bem estabelecido o efeito que estas propriedades têm nas curvas de equilíbrio termodinâmico (Folie e Radosz, 1995; Krenz, 2005). A estimação do BIP global do sistema PEBD/etileno foi realizada a partir da solução de um problema de otimização onde foi minimizado o erro quadrático entre o valor experimental (exp) e o valor calculado (calc) pelo modelo PC-SAFT, conforme definido na Equação 3.

$$
F O=\left(P^{e x p}-P^{\text {calc }}\right)^{2}
$$

onde $P$ é a pressão de equilíbrio termodinâmico. Os valores de pressão foram calculados utilizando-se um algoritmo de equilíbrio do tipo Bolha $\mathrm{P}$, sendo esta a variável escolhida por ser a única o único valor experimental (além da composição ligada a ela) disponível na condição de equilíbrio. Desta forma, cada BIP estimado nesta otimização está vinculado a um conjunto de pressão, temperatura e propriedades morfológicas do polímero.

\subsection{ARQUITETURA E TREINAMENTO DA REDE NEURAL}

As RNA são programas computacionais inspirados na maneira como o cérebro humano processa as informações. Elas são formadas por unidades de processamento chamadas neurônios, com pesos associados a eles, equivalentes às sinapses num cerebro real. No presente trabalho, foi escolhida uma RNA do tipo feedforward backpropagation com uma camada oculta e uma camada de saída (aproximador universal de funções), como mostrado de forma ilustrativa na Figura 1. As entradas são multiplicadas pelos pesos conectados, somadas e finalmente processadas por uma função de ativação para gerar a saída.

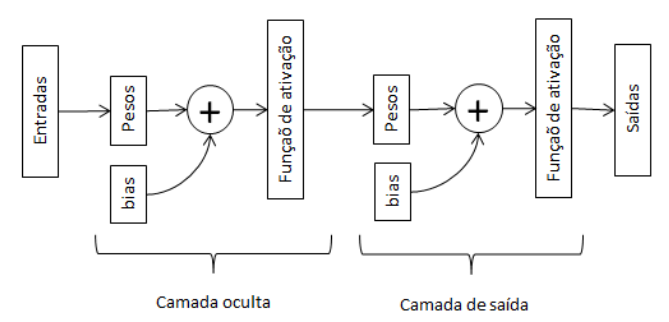

Figura 1 - Estrutura da RNA do tipo backpropagation usada nesse trabalho.

As entradas de rede são a pressão [877,11 a 1868,59 bar], a temperatura [383,15 a 523,15 K], o peso molecular médio [106000 a $236000 \mathrm{~g} / \mathrm{mol}$ ] e a polidispersão [2,74 a 12,00] do polímero. A única saída é o BIP. A RNA foi construída no Matlab® e o algoritmo de treinamento utilizado foi o Levenberg-Marquardt. As funções de ativação escolhidas para a camada oculta e para a camada de saída foram a sigmoide (logsig) e a linear (purelin), respectivamente. A definição do número de neurônios da camada oculta foi realizada de forma empírica. Foram escolhidas 8 topologias de RNA para treinamento e a selecionada foi aquele que apresentou o melhor equilíbrio entre o número de neurônios e o $\mathrm{R}^{2}$. A Figura 2a apresenta os resultados de treino, onde se pode observar o coeficiente de determinação $\left(\mathrm{R}^{2}\right)$ e o tempo necessário de treinamento para cada rede proposta, tempo este que variou de forma insignificante em relação do número de neurônios. Observa-se que a partir de 12 
neurônios na camada oculta, a variação do valor do $\mathrm{R}^{2}$ não é tão significativa. Em função disto, foi selecionada para modelagem a rede com 12 neurônios, cuja topologia é apresentada na Figura 2b.

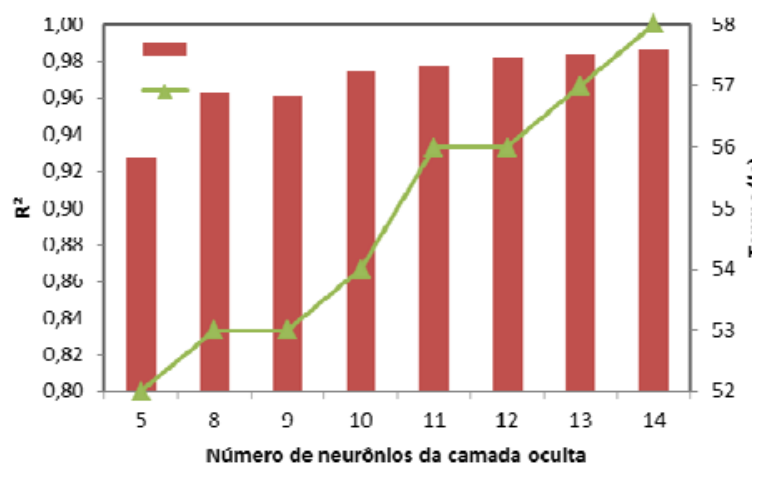

(a)

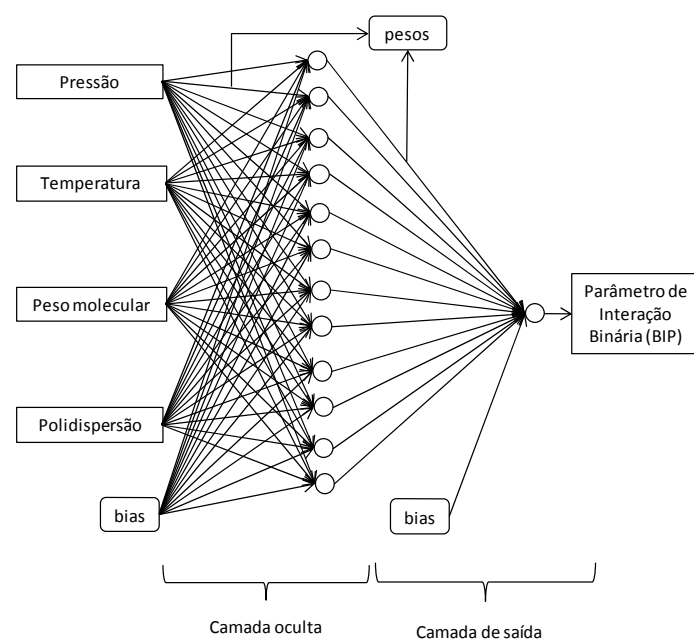

(b)

Figura 2 - a) Resultados de treino com diferentes camadas ocultas e b) topologia da rede neural com melhores resultados de treino.

\subsection{AVALIAÇÃO DO TREINAMENTO E DA PREDIÇÃO}

Foram utilizados 264 dados experimentais para treinamento (85\%) e 47 dados para testar (15\%) (validação cruzada) a rede treinada. A avaliação do desempenho da RNA em se ajustar aos dados experimentais e predizer os dados utilizados para teste foi feita utilizando o gráfico da $1^{\circ}$ bissetriz e do ajuste linear. Os BIPs preditos na etapada de treinamento da RNA são mostradas na Figura 3a e o resultados da sua capacidade de predição dos dados de teste estão registrados na Figura 3b. É possível perceber a boa concordância entre o BIP alvo e o valor calculado pela RNA. O espalhamento em torno da curva da $1^{\circ}$ bissetriz aponta que não há uma tendência ou desvio permanente entre o valor alvo e o valor calculado. Ou seja, não há uma tendência à super ou subestimação do valor do BIP calculado pela rede. Além disso, as melhores regressões lineares feitas entre o valor alvo e calculado geraram retas com coeficiente angular próximo de 1 (um) (0,982 para treino e 0,956 para o teste) e coeficientes angulares próximos a zero (0,000698 para treino e 0,00179 para teste). Isso representa retas que dividem o quadrante praticamente ao meio e passam pela origem dos eixos, fato que faz as curvas da $1^{\circ}$ bissetriz e melhor regressão linear praticamente se sobreporem. 


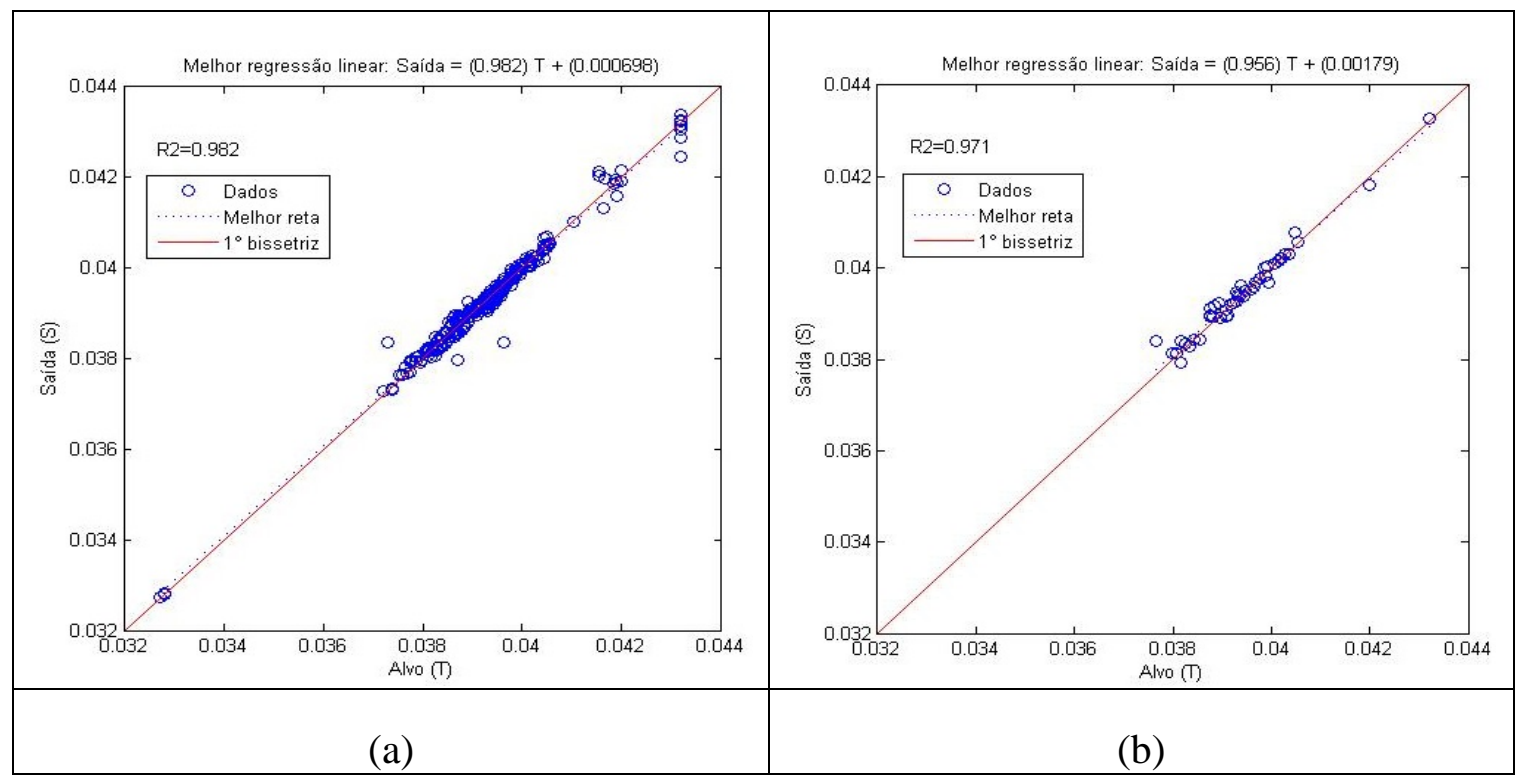

Figura 3 -a) Comparação entre BIPs preditos e experimentais após o treinamento da rede e b) no teste da rede.

A capacidade de predição da RNA desenvolvida foi avaliada utilizando o R $^{2}$ (Figura 4) e do desvio relativo (DR) (Equação 4).

$$
D R(\%)=100 \frac{\sum_{i=1}^{n}\left|B I P_{i}^{\text {exp }}-B I P_{i}^{R N A}\right|}{B I P_{i}^{\exp }}
$$

Os desvios relativos percentuais dos dados de treino e teste localizam-se nos intervalos de 0 a 3,226\% e 0 a 1,933\%, respectivamente. Os desvios médios relativos obtidos durante o treinamento e teste foram $0,23 \%$ e $0,05 \%$. Os coeficientes de determinação $\left(R^{2}\right)$ obtidos também são satisfatórios. Ou seja, grande quantidade dos dados consegue ser explicada pelos regressores presente no modelo. Observa-se ainda que o erro máximo foi pouco maior que $3 \%$, o que nos leva a considerar que o modelo foi bem ajustado.

Pelos resultados apresentados na Figura 4, verifica-se que os resíduos não são correlacionados. A distribuição normal com média próxima de zero observada na Figura 4a, além de não haver nenhum comportamento sistemático do resíduo com relação aos dados experimentais (Figura 4b), destacam o bom ajuste dos parâmetros.
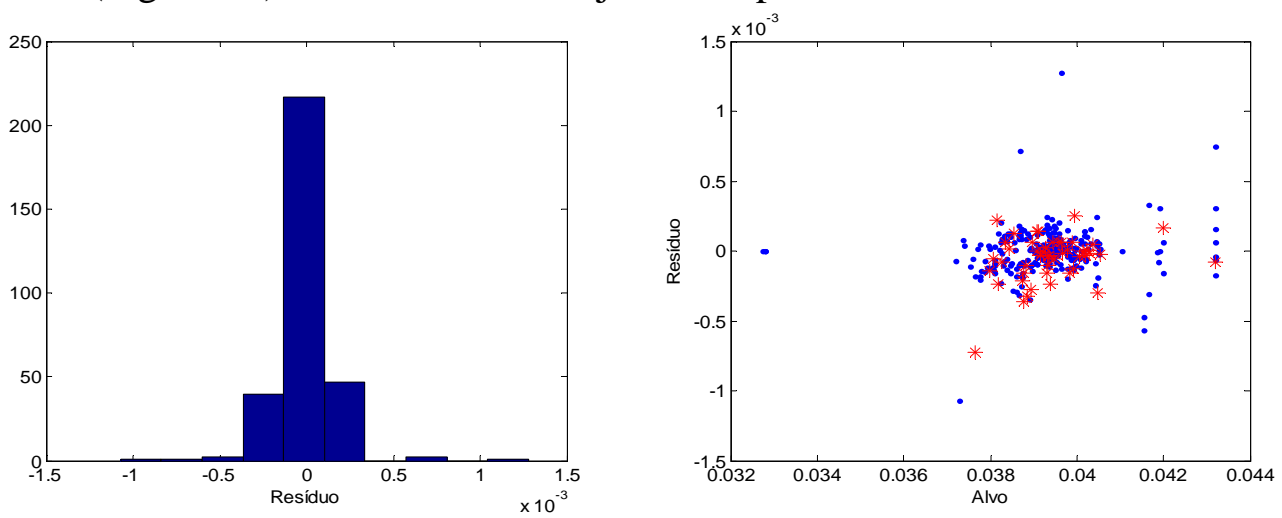

Figura 4-a) Distribuição estatística do resíduo e b) seu espalhamento. 
Os BIPs preditos pela RNA foram utilizados para obter o diagrama de equilíbrio líquido-líquido para o sistema polietileno/etileno. A Figura 5 apresenta os resultados da modelagem do equilíbrio utilizando os BIP experimentais (BIP-Exper) e os preditos pela RNA (BIP-RNA). É possível se observar que em alguns pontos a $250^{\circ} \mathrm{C}$ a equação de estado não foi tão aderente aos dados experimentais, embora percentualmente o desvio máximo seja inferior à $9 \%$, o que representa uma boa modelagem. Por outro lado, os valores preditos pela equação de estado utilizando BIP-Exper ou BIP-RNA praticamente si sobrepuseram em toda a região avalida, indicando que o que o uso da RNA se mostrou uma ferramenta bastante adequada para predição do BIP e descrição do equilíbrio.

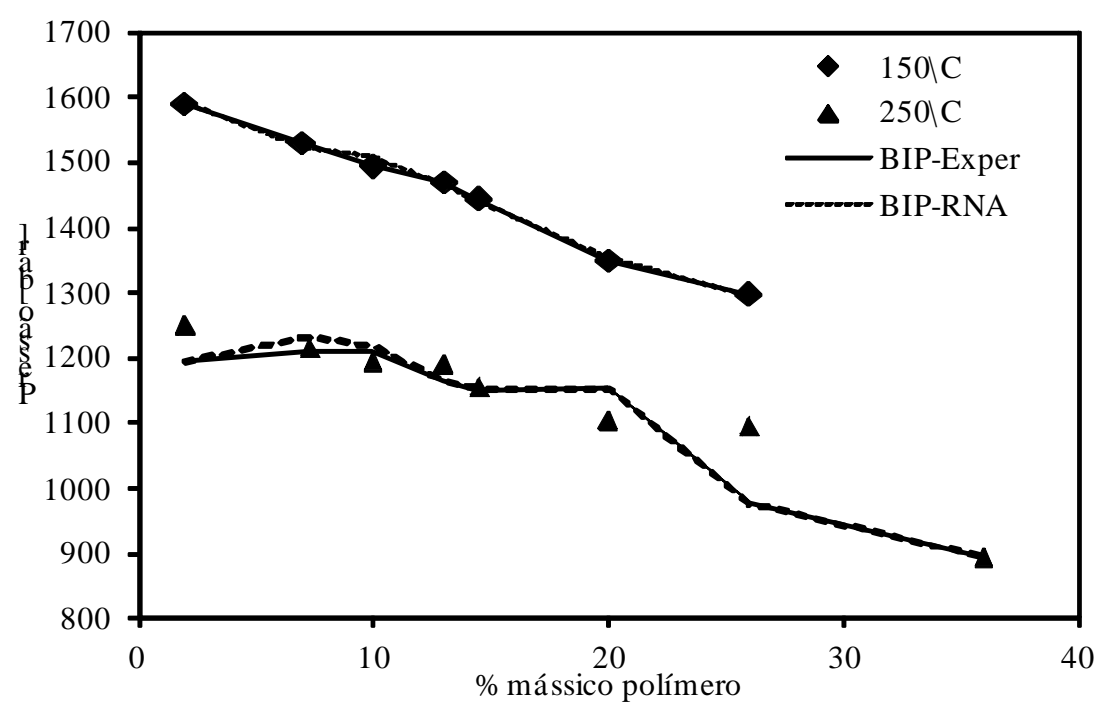

Figura 5 - Comparação entre curvas de equilíbrio líquido-líquido para o sistema PEBD/etileno calculadas pelo modelo PC-SAFT com diferentes BIPs: ajustado ao dado experimental (BIP-Exper) e predito pela RNA (BIP-RNA).

\section{CONCLUSÃO}

As redes neuronais artificiais se mostraram uma ferramenta de grande valia para predição do BIP com um alto nível de exatidão. Apesar de utilizado apenas em uma solução polimérica contendo polietileno/etileno, o método possui ampla aplicabilidade, e pode se estender a outros sistemas poliméricos. Essa estratégia permite que propriedades e curvas de equilíbrio possam ser calculadas utilizando o BIP predito por uma RNA, a partir de dados de entrada facilmente mensuráveis. De um ponto de vista mais amplo essa abordagem aumenta significativamente o poder de predição da equação de estado e consequentemente sua importância acadêmica e industrial.

\section{REFERÊNCIAS BIBLIOGRÁFICAS}

FOLIE, B.; RADOSZ, M. Phase Equilibria in High-Pressures Polyethylene Technology, Ind. Eng. Chem. Res., v. 34, p. 1501-1516, 1995.

GHARAGHEIZI, F.; ESLAMIMANESH, A.; MOHAMMADI, A. H.; RICHON, D. Determination of critical properties and acentric factors of pure compounds using the artificial neural network group contribution algorithm. J. Chem. Eng. Data, v. 56, p. 24602476, 2011 a. 
GHARAGHEIZI, F.; ESLAMIMANESH, A.; MOHAMMADI, A. H.; RICHON, D. Representation/Prediction of solubilities of pure compounds in water using artificial neural network - group contribution method. J. Chem. Eng. Data, v. 56, p. 720-726, 2011 b.

GHARAGHEIZI, F.; ESLAMIMANESH, A.; MOHAMMADI, A. H.; RICHON, D. Use of artificial neural network-Group contribution method to determine surface tension of pure compounds. J. Chem. Eng. Data, v. 56, p. 2587-2601, 2011c.

GROSS, J.; SADOWSKI, G. Perturbed-Chain SAFT: An equation of state based on a perturbed theory for chain molecules, Ind. Eng. Chem. Res., 40, 1244-1260, 2001.

GUERRIERI, Y.; PONTES, K. V.; MEYBERG, G.; COSTA, N.; EMBIRUÇU, M. A survey of equations of state for polymers. INTECH, chapter 16, 2012.

HASLAM, A. J.; GALINDO, A.; JACKSON, G. Prediction of binary intermolecular potential parameters for use in modelling fluid mixtures. Fluid Phase Equilib., v. 266, p. 105-128, 2008.

HOSSEINI, S. M.; FAZLALI, A. R.; ZAHEI, G. R. Critical properties of hydrocarbon mixtures by artificial neural network and Peng-Robinson EOS, ARPN J. Eng. Appl. Sci., v. 3, n. 6, 2008.

HUDSON, G. H.; MCCOUBREY, J. C. Intermolecular forces between unlike molecules. Trans. Faraday Soc, v. 56, 761-766, 1960.

KRENZ, R. A. Behaviour of Polydisperse Polyethylene Solutions using the Modified Sanchez-Lacombe Equation of State. 722f. Ph.D. Thesis, University of Calgary, Calgary, Canada, 2005.

MOGHADASSI, A.; FAHIME, P.; HOSSEINI, S. M.; SHARIFI, A. Prediction of pvt properties of ammonia by using artificial neural network and equations of state, ARPN J. Eng. Appl. Sci., v. 3, n. 6, 2008.

NAMI, F.; DEYHIMI, F. Prediction of activity coefficients at infinite dilution for organic solutes in ionic liquids by artificial neural network. J. chem. Thermodyn., v. 43, p. 22-27, 2011.

PRASAD, Y.; BHAGWAT, S. S. Simple neural network models for prediction of physical properties of organic compounds. Chem. Eng. Technol., v. 25, p. 1041-1046, 2002.

SANJARI, E.; LAY, E. N. Estimation of natural gas compressibility factors using artificial neural network approach, J. Nat. Gas Sci. Eng., v. 9, p. 220-226, 2012.

SMITH, J. M.; VAN NESS, H. C.; ABBOTT, M. M. Introdução à termodinâmica da engenharia química, São Paulo: Editora LTC, 2007.

YOUSEFI F.; KARIMI, H. Application of equation of state and artificial neural network to prediction of volumetric properties of polymer melts, J. Ind. Eng .Chem., v. 19, p. 498-507, 2013. 